\title{
Trainees need more psychiatric teaching sessions and role models: exposure to psychiatry in the Foundation Programme
}

\author{
Adam Moreton, ${ }^{1}$ Andrew Collier ${ }^{2}$
}

The Psychiatrist (2013), 37, 207-209, doi: 10.1192/pb.bp.112.041459

${ }^{1} \mathrm{NHS}$ North West, Manchester;

${ }^{2}$ Mersey Care NHS Trust, Liverpool

Correspondence to Adam Moreton (a.moreton@doctors.org.uk)

First received 9 Sep 2012, final revision

14 Jan 2013, accepted 15 Jan 2013

\begin{abstract}
Aims and method To determine the provision of teaching in psychiatry for foundation doctors up to the point of making specialty applications. Data for the cohort of foundation doctors entering training in 2010 were collected from teaching programmes across the Mersey Deanery and North Western Foundation Schools.
\end{abstract}

Results In the 17 hospitals that provided data, 'protected teaching' totalled $2354 \mathrm{~h}$; $1.8 \%$ of time was dedicated to psychiatry, with 4 hospitals providing no teaching on mental health topics. The mean duration of psychiatry teaching was higher in university teaching hospitals ( $3 \mathrm{~h} 34 \mathrm{~min}$ ) than district general hospitals ( $2 \mathrm{~h} 57 \mathrm{~min}$ ); and almost a quarter of teaching sessions were titled only 'psychiatry'.

Clinical implications For many foundation doctors their only experience of psychiatry will be through teaching sessions, and this is potentially the only time to change opinions and build interest in the specialty. Psychiatrists need to take a more active role in the provision of high-quality teaching for foundation doctors and become the visible role models which are currently lacking.

Declaration of interest A.M. was the BMA Junior Doctors Committee representative to the UK Foundation Programme Board and Foundation School Directors' Committee during 2011-2012.
A study of medical students reported that the influence of a role model was considered a 'moderately influencing' factor when choosing a specialty (on a par with job availability and monetary reward). ${ }^{1}$ Additionally, among UK doctors the influence of 'a particular teacher or department' was a statistically significant factor that affected their career choice. $^{2}$

With most psychiatric care being provided in National Health Service trusts separate to that of other medical specialties and often being located on different sites to acute hospitals, ${ }^{3}$ foundation year (FY) doctors working in psychiatry can feel isolated from their peers working in acute medical specialties. ${ }^{4}$ How can psychiatrists overcome the barriers separating them from the other medical specialties and break into this group of trainee doctors, become role models, and influence their future choice of specialty?

Currently, only $3.5 \%$ of total FY posts in the UK are in psychiatry, ${ }^{5}$ although there are plans to increase this number to $7.5 \%$ in both years (FY1 and FY2) of the programme. ${ }^{6}$ However, unless an FY doctor rotates through a job in psychiatry, there are limited routes through which they can be reached by prospective role models and gain exposure to the specialty. This study examined the prevalence of psychiatry teaching within the 'protected teaching' programmes provided by hospitals hosting FY doctors in the north-west of England. As a comparator, the teaching sessions relating to medical and surgical specialties have been analysed.

\section{Method}

\section{Data collection}

With the agreement of the Mersey and North Western Foundation Schools' directors, each acute hospital hosting FY doctors was contacted by email about their protected teaching programmes for the cohort of FY doctors beginning work in August 2010 (entering specialty training in August 2012). Data were collected on a hospital rather than trust basis as a single acute trust can house a number of hospitals, each with their own unique teaching programme.

Information on teaching sessions was requested to determine the 'taught programme' exposure to different specialties for the 2010 cohort; from entry to the Foundation Programme up to the point of making an application for specialty training (December 2011). Initial requests for information were followed up by two further emails when no response was received. Hospitals were 
informed that the data they submitted would be anonymised and it would not be used to determine the quality of their teaching programmes. The entire teaching programme was requested, with no reference being made to a specific psychiatry analysis.

\section{Data analysis}

Where a hospital utilised a 'rolling programme' with sessions repeating to allow as many FY doctors as possible to attend, each session was only counted once in the analysis, and any cancelled sessions were not included. Additionally, 'grand round' sessions were excluded as they are not specifically for FY doctors and often titles were not submitted.

If the specialty to which the teaching sessions pertained was not immediately clear, a decision was made based on the specialty of the presenter, or the question was asked 'What specialty would this session inspire the doctor to pursue?' For example, sessions on end-of-life care or the Liverpool Care for the Dying Patient pathway were categorised as 'medicine', as palliative care is a medical subspecialty.

Sessions on use of the Mental Capacity Act 2005 were not classified as psychiatry teaching sessions as the skills learnt are used on a daily basis by non-psychiatrists in most specialties.

\section{Results}

A total of 17 out of 27 (63\%) hospitals in the north west responded and provided teaching programmes for the 2010 cohort of FYl doctors up to the point of making specialty applications; 10 hospitals did not reply to the emails. One hospital was only able to provide the programme for their FY2 doctors.

Data for 1728 teaching sessions totalling $2354 \mathrm{~h}$ were extracted and analysed, with $43 \mathrm{~h} 15 \mathrm{~min}(1.8 \%)$ of the time dedicated to psychiatry and $1009 \mathrm{~h} 50 \mathrm{~min}(42.9 \%)$ spent on medical or surgical topics. The remainder of the time was spent broadly on: other medical specialties (11.9\%), clinical governance/critical appraisal/induction (10.7\%), prescribing skills (7.8\%), professionalism/leadership/legal (6.8\%), careers (5.1\%), private study/portfolio (3.3\%), communication skills $(0.8 \%)$ and unknown $(8.8 \%)$.

At least one session of teaching was dedicated to a mental health topic in 13 of the 17 responding hospitals comprising 5 district general hospitals and 8 university teaching hospitals. The four hospitals that did not provide any psychiatry teaching were district general hospitals; of these, one provided data only for its FY2 doctors and so we cannot exclude such a session being taught in the FY1 year.

\section{Psychiatry teaching time}

The mean total time dedicated to mental health topics across the 13 hospitals was $3 \mathrm{~h} 20 \mathrm{~min}$ (range $45 \mathrm{~min}-5 \mathrm{~h} 45 \mathrm{~min}$ ). Continuing to exclude the hospitals with zero hours of psychiatry teaching, the mean number of hours still differed between both hospital types, with $2 \mathrm{~h} 57 \mathrm{~min}$ (range $1-4 \mathrm{~h}$ ) in district general hospitals and $3 \mathrm{~h} 34 \mathrm{~min}$ (range $45 \mathrm{~min}-$ $5 \mathrm{~h} 45 \mathrm{~min}$ ) in university teaching hospitals.
Across those hospitals with psychiatry teaching, 7 out of 31 mental health sessions (23\%) were titled only 'psychiatry' or something similarly vague.

On average, 6 teaching sessions (range 0-21) were left unfilled during the first 16 months of the Foundation Programme. Only two hospitals had no empty slots within their protected teaching. Unfilled sessions were those marked as 'cancelled' or blank, and any 'private study' sessions were also included. Any unfilled teaching slots around national holidays or job changeover were discounted; additionally, all recorded as 'TBC' (to be confirmed) were assumed to have taken place.

\section{Discussion}

Teaching time dedicated to psychiatry compared with medical or surgical topics was low considering that almost all doctors will need some knowledge of psychiatry, regardless of the specialty they choose to pursue, and the Foundation Programme is likely the last time a junior doctor will experience a generic teaching programme before entering specialist training. The fact that some doctors may have received no formal teaching in psychiatry is worrying as teaching programmes should be mapped to the Foundation Programme curriculum, ${ }^{7}$ which has elements related to psychiatric illness. It is possible, however, that this teaching may have occurred in the last two rotations of the programme which were not included in this analysis, thereby fulfilling the needs of the curriculum, but not giving the opportunity to influence future career choice.

All of the hospitals with no psychiatry teaching in the first 16 months of the Foundation Programme were district general hospitals. Where psychiatry teaching did take place, the mean amount of time dedicated to mental health topics in university teaching hospitals was 37 min higher than that of district general hospitals. Most teaching programmes for this analysis were provided by the latter, although the majority of hospitals with psychiatry teaching sessions were university teaching hospitals.

Also of concern was the fact that almost a quarter of the limited sessions on mental health topics were simply titled 'psychiatry'. Although the sessions may have covered specific areas such as risk assessment and psychopharmacology, using a title such as this implies that the whole specialty can be covered in a single sitting. This does little to improve the image of psychiatry against other medical specialties, where such a broad remit for a teaching session would not be commonplace.

Previous research has shown that the perception of a specialty developed during medical school can be altered in the postgraduate years. About a quarter of newly qualified doctors change their career choice in their first 3 years of work, with more choosing psychiatry as their preferred specialty by the third year compared with the first. ${ }^{8}$

A survey of trained and trainee psychiatrists ${ }^{9}$ showed that those working in psychiatry 'do not have time to teach medical students', although they do see teaching as 'an integral part of their work'. Even if working practices are changed, job plans amended and rotas altered to allow trainees and consultants to have time to teach, at present it is difficult to imagine how, in such restricted teaching 
programmes, these doctors will find the opportunities to do so. To improve the amount of psychiatry teaching provided there will need to be buy-in from many parties to facilitate this, not just the psychiatrists.

The specialty recruitment round relevant to this cohort (entry in August 2012) resulted in a 86\% fill rate across deaneries in England and Wales for core psychiatry training (CT1). ${ }^{10}$ The Royal College of Psychiatrists' recruitment strategy aims to increase this fill rate to $95 \%$ as part of a 5-year campaign targeting medical students and FY doctors. ${ }^{11}$ The argument for FY doctors to receive more psychiatry teaching solely to recruit more psychiatrists is unlikely to garner much support from those designing the teaching programmes. What could persuade them is a strong educational case. A survey of junior medical staff working in an emergency department over 2 years demonstrated that a large proportion 'lacked knowledge and confidence in the assessment of mental health patients, and they identified training needs in terms of knowledge and skills, ${ }^{12}$ Although this was a small study, there are plans to follow it up after instigation of training sessions to address these deficits and the results will be of interest. What is needed to support such an educational case is research showing that an increase in psychiatry teaching yields new skills, develops existing ones and gives greater confidence in using them in junior doctors' day-to-day work, across a variety of specialties.

This analysis has shown that across the 17 hospitals responding there was an average of 6 potential teaching slots in the rota that could be filled by the opportunistic psychiatrist. This number could be higher as data on cancelled or free sessions were not specifically requested; and so this information may not have been supplied by all the hospitals as many of the teaching programmes did not have any sessions specifically recorded as cancelled. It is unrealistic for a trainee or consultant to be 'on-call' to provide teaching at a moment's notice, but by informing the hospital's postgraduate education centre of the doctor's willingness to fill an empty teaching slot the prevalence of psychiatry teaching given to FY doctors can potentially be increased and doctors may be inspired to follow a career they may not have considered.

Even when $7.5 \%$ of FY posts become rotations in psychiatry, there will still be a significant number of doctors who do not get any experience in the specialty. At a time when FY doctors need role models to inspire their career choice, many will not have the opportunity to interact with, question or be guided by an ambassador for psychiatry. Even if they do, it could be for as little as $45 \mathrm{~min}$ out of the 100-plus hours of formal postgraduate teaching they receive before choosing a specialty.

\section{About the authors}

Dr Adam Moreton MB ChB (Hons) Post-F2 OOPE (out-of-programme experience), Medical Leadership and Management Fellow, NHS North West, Manchester. Dr Andrew Collier MB ChB BSc (Hons) CT3 psychiatry trainee, Mersey Care NHS Trust, Liverpool.

\section{References}

1 Rehman A, Rehman T, Shaikh MA, Yasmin H, Asif A, Kafil H. Pakistani medical students' specialty preference and the influencing factors. J Pak Med Assoc 2011; 61: 713-8.

2 Goldacre MJ, Turner G, Lambert TW. Variation by medical school in career choices of UK graduates of 1999 and 2000. Med Educ 2004; 38 249-58.

3 Hafferty JD. Recruitment crisis - poor marketing or product failure? (letter). Psychiatrist 2012; 36: 271.

4 Welch J, Bridge C, Firth D, Forrest A. Improving psychiatry training in the Foundation Programme. Psychiatrist 2011; 35: 389-93.

5 Lowe J, Rands G. Current position of psychiatry in UK foundation schools. Psychiatrist 2012; 36: 65-8.

6 Jaques $\mathrm{H}$. Royal college launches five year plan to increase applicants to psychiatry. BMJ Careers, 2012.

7 The UK Foundation Programme Office. The UK Foundation Programme Curriculum. Crown Copyright, 2010 (http://www.foundationprogramme. nhs.uk/download.asp?file=Foundation_Curriculum_2011_WEB.pdf)

8 Goldacre MJ, Lambert TW. Stability and change in career choices of junior doctors: postal questionnaire surveys of the United Kingdom qualifiers of 1993. Med Educ 2000; 34: 700-7.

9 Korszun A, Dharmaindra N, Koravangattu V, Bhui K. Teaching medical students and recruitment to psychiatry: attitudes of psychiatric clinicians, academics and trainees. Psychiatrist 2011; 35: 350-3.

10 UK Foundation Programme Office. National F2 Career Destination Survey (2012). UKFPO, 2012.

11 The Royal College of Psychiatrists. Recruitment Strategy. RCPsych, 2012

12 Gordon JT. Emergency department junior medical staff's knowledge, skills and confidence with psychiatric patients: a survey. Psychiatrist 2012; 36: 186-8. 